\title{
A One-Year Hospital Based Prospective Study of Sickle Cell Disease from One Capital Area of Kuwait by HPLC
}

\author{
AlDallal $S^{*}$ and Abdulsalam S
}

Amiri Hospital, Kuwait

*Corresponding author: Dr. Salma AlDallal, 25, Kuwait City, Kuwait, Amiri Hospital, 150300, Tel: +96590981981, E-mail: dr.s.aldallal@outlook.com

Citation: AlDallal S, Abdulsalam S (2016) A One-Year Hospital Based Prospective Study of Sickle Cell Disease from One Capital Area of Kuwait by HPLC. J Hematol Blood Disord 2(2): 203. doi: 10.15744/2455-

7641.2.203

Received Date: May 15, 2016 Accepted Date: June 27, 2016 Published Date: June 29, 2016

\begin{abstract}
Background \& Objectives: Haemoglobinopathies are inherited disorders of haemoglobin synthesis that are responsible for significant morbidity and mortality all over the world. Sickle cell disease (SCD) is clinically one of the most important haemoglobinopathies. The disease is characterized by red blood cell abnormality including sickling and rigidity. The aim of retrospective study was to determine the different fractions of haemoglobins that appear in a chromatogram of patients with sickle cell disease and to measure different types of haemoglobins in one capital area in 2015.

Methods: HPLC records of 144 patients with SCD were retrieved from hospital records. Records from 34 control patients were also retrieved. About 178 subjects were included with mean age of 28.2 (SD 20.16) years.

Results: $76.3 \%$ of patients had an HbAS phenotype, whilst $23.6 \%$ were HbSS. Irrespective of their gender or age; differences were observed in $\mathrm{HbA}, \mathrm{HbS}$ and $\mathrm{HbF}$ levels in patients compared to controls.

Interpretation \& Conclusion: Knowledge of the prevalence of haemoglobin phenotype patterns underpins screening, diagnosis and treatment strategies within our population.

Keywords: Haemoglobinopathies; Haemoglobin pattern; Haemoglobin synthesis; Sickle cell disease; HbAS phenotype; $\beta$-globin List of Abbreviations: SCD: Sickle cell disease; HbS: Hemoglobin S; HPLC: High-Performance Liquid Chromatography
\end{abstract}

\section{Introduction}

Haemoglobinopathies are inherited disorders characterised by either reduced production of one or more globin chains in thalassaemia or an abnormality in the structure of haemoglobin, such as in sickle cell anaemia [1]. Sickle cell disease (SCD) is a common hereditary haemoglobinopathy, accounting for about $70 \%$ of the world's major haemoglobinopathies [2,3]. A point mutation in the beta globin chain of haemoglobin results in substitution of valine for glutamic acid at the sixth position [4]. Homozygous SS (sickle cell anaemia) is generally considered the most severe form of SCD. Compound heterozygotes, in which haemoglobin $\mathrm{S}(\mathrm{HbS})$ is combined with a different mutation in the second $\beta$-globin gene display variable phenotypes. The carrier state (HbAS) does not cause clinically significant disease [5], is asymptomatic and carriers are protected from malaria infection $[6,7]$. The clinical complications of SCD include chronic haemolytic anaemia, painful episodes of vasoocclusion, permanent risk of infections, acute chest syndrome and cumulative damage of multiple organs [8-10]. SCD occurs primarily among people of subSaharan African, Middle Eastern, Mediterranean and Indian descent [11,12].

The primary pathophysiology is based on the polymerization of deoxyHbS [13]. A reduction in $\mathrm{pH}$ enhances $\mathrm{HbS}$ polymerization, as does a rise in temperature [14]. The concentration of HbS in the red blood cells is also of great importance, with higher concentrations of $\mathrm{HbS}$ leading to more rapid polymerization. Another determinant of the tendency for polymerization is the presence of other haemoglobins, with $\mathrm{HbA} 2$ and $\mathrm{HbF}$ limiting the $\mathrm{HbS}$ polymerization to a greater extent than $\mathrm{HbA}$ and $\mathrm{HbC}$. Homozygous patients have no $\mathrm{HbA}$, an $\mathrm{HbS} \%$ greater than $85 \%$, an elevated $\mathrm{HbF} \%$ and a normal $\mathrm{HbA}_{2} \%$.In people with $\mathrm{HbAS}$, the $\mathrm{HbS} \%$ is approximately $40 \%$. In patients with $\mathrm{HbSC}$, the $\mathrm{HbS} \%$ is about 10 to $15 \%$ higher and the mean corpuscular haemoglobin concentration (MCHC) is elevated, explaining why people with HbSC cab be severely affected $[15,16]$.

Over the last few decades, there have been a number of studies indicating that anaemia is a significant public health problem in the State of Kuwait [17]. A comprehensive electrophoretic screening of the Kuwaiti population was conducted in a tertiary hospital in Kuwait and showed that $6 \%$ of patients were heterozygous for HbS, while $0.9 \%$ was homozygous [18]. 
Numerous techniques are used to screen for sickle cell trait or SCD, such as high-performance liquid chromatography (HPLC), haemoglobin electrophoresis, sickle solubility test, capillary electrophoresis, globin chain electrophoresis and DNA sequencing $[19,20]$. However, it is essential to emphasise that in conjunction with any of these techniques, evaluation of the peripheral blood smear, as well as correlation with the results of a complete blood count (CBC) are crucial since many of the clinically significant haemoglobin disorders show distinctive peripheral blood findings, and are often co-inherited. HPLC has replaced alkaline electrophoresis as the main screening method of haemoglobinopathies. The consistency and reproducibility of results has made HPLC the method of choice for quantifying $\mathrm{HbA}_{2}$ and $\mathrm{HbF}$ for laboratory identification of haemoglobinopathies [21].

The aim of the present study was to determine fractions of haemoglobins that appear in a chromatogram and to measure levels of $\mathrm{Hb} \mathrm{A}, \mathrm{Hb} \mathrm{F}$ and $\mathrm{Hb} \mathrm{A}_{2}$ among SCD patients in one capital area during a one year period.

\section{Materials and Methods}

\section{Study Design}

This retrospective study was carried out in the Hematology Laboratory Department, Amiri Hospital, Kuwait, for a one year period (2015). One forty-four sickle cell disease patients from adults and pediatric groups that presented with clinical anemia were referred for HPLC analysis. Records were also taken from 34 control patients. Medical history was retrieved from the hospital's medical records department, and each patient was examined by a haematologist. Data collected from patients records included age, gender, sickle solubility test, and percentage of haemoglobin fraction.

In this study, target group adopted is, anaemic patients referred for HPLC analysis (HPLC-Waters; U.A.E) attending Amiri Hospital, Kuwait for a one year period (2015). Records of one-forty four sickle cell disease patients from adults and paediatric groups were retrieved from hospital data base for patients who diagnosed or suspecting to have a sickle cell haemoglobinopathies and confirmed by positive sickling test. Records were also taken from 34 control patients with healthy hospital records.

\section{Ethical Issues}

Ethical clearance was given by the Research Committee in the Kuwait Ministry of Health.

\section{Statistical Analysis}

Statistical analysis was performed by Statistical Package for Social Science Software (SPSS) version 19 software. A Chi Square test was conducted to assess distribution of categorical variables (e.g. gender, age group, study group), and a Student's t-test was used in order to compare means of scale variable between groups. Statistical significance was set at $\mathrm{P} \leq 0.05$.

\section{Results}

\section{Demographic characteristics of patients and control groups}

As illustrated in Table 1, a total of 178 subjects participated in the study; 144 patients and 34 controls, with approximately equal numbers of men and women in both groups. The mean age for participants was 28.2 (SD 20.16).

\begin{tabular}{|c|c|c|c|c|}
\hline & \multicolumn{2}{|c|}{ Patient N = 140 } & \multicolumn{2}{c|}{ Control N = 34 } \\
\hline Age & Male N = 70 & Female N = 70 & Male N = 16 & Male N = 16 \\
\hline$\leq 20$ & $38(31.7)$ & $25(20.8)$ & $8(23.5)$ & $6(17.6)$ \\
\hline $21-40$ & $17(14.2)$ & $27(22.5)$ & $7(20.6)$ & $6(17.6)$ \\
\hline$\geq 41$ & $17(14.2)$ & $20(8.3)$ & $1(2.9)$ & $6(17.6)$ \\
\hline
\end{tabular}

Table 1: Demographics

\section{Frequency of haemoglobin phenotype (HbAS, HbSS) among patient groups}

The frequency of each phenotype within the study group showed, 110 participants (76.3\%) having haemoglobin phenotype HbAS, and 34 (23.6\%) having haemoglobin phenotype HbSS.

There was a significantly lower mean $\%$ of $\mathrm{HbA}$ in $\mathrm{HbAS}$ patients in comparison with the control group, while $\mathrm{HbA}$ was not found in any patients in the HbSS group. There was no significant difference in the mean \% of $\mathrm{HbA}_{2}$ in either the HbAS or HbSS patient groups when compared with the control group (Table 2), or in the mean $\%$ of $\mathrm{HbA}_{2}$ between $\mathrm{HbAS}$ and $\mathrm{HbSS}(\mathrm{p}=0.73$ ). $\mathrm{HbS}$ and $\mathrm{HbF}$ phenotype were only found in the two patient groups. A highly significant difference was observed in the mean \% of HbS between $\mathrm{HbAS}$ and HbSS $(\mathrm{p}<0.05)$. 


\begin{tabular}{|c|c|c|c|c|}
\hline Pattern & & HbAS & HbSS & Control \\
\hline \multirow{3}{*}{ HbA } & No. & 110 & 34 & 34 \\
\cline { 2 - 5 } & Mean \% & 59.1 & 0 & 97.53 \\
\cline { 2 - 5 } & SD & 14.35 & 0 & 1.04 \\
\hline \multirow{3}{*}{ HbA $_{2}$} & No. & 110 & 34 & 34 \\
\cline { 2 - 5 } & Mean \% & 2.43 & 2.44 & 2.46 \\
\cline { 2 - 5 } & SD & 1.02 & 1.10 & 1.04 \\
\hline \multirow{3}{*}{ HbF } & No. & 47 & 34 & 0 \\
\cline { 2 - 5 } & Mean \% & 12.1 & 83.21 & 0 \\
\cline { 2 - 5 } & SD & 11.96 & 593.7 & 0 \\
\hline \multirow{3}{*}{ HbS } & No. & 110 & 34 & 0 \\
\cline { 2 - 5 } & Mean \% & 43.2 & 67.04 & 0 \\
\cline { 2 - 5 } & SD & 19.4 & 21.36 & 0 \\
\hline
\end{tabular}

Table 2: The mean level of haemoglobin $\mathrm{A}, \mathrm{A}_{2}, \mathrm{~F}$ and $\mathrm{S}$ level in HbAS, HbSS patients compared with control group

No difference was observed in the distribution of phenotypes in patients according to gender (Table 3) or according to age (Table 3). However, female patients were more likely to have a higher mean $\%$ of $\mathrm{HbA}(\mathrm{p}=0.08)$ and men were more likely to have a higher mean $\%$ of $\mathrm{HbA}_{2}(\mathrm{p}=0.03)$ and $\mathrm{HbS}(\mathrm{p}=0.04)$. Higher mean $\%$ of HbS was found in older patients, compared to younger patients $(\mathrm{p}=0.10$; Table 4$)$.

\begin{tabular}{|c|c|c|c|c|c|c|}
\hline Phenotype & \multicolumn{2}{|c|}{ Gender } & \multicolumn{4}{c|}{ Age } \\
\hline & Male & Female & $<5$ & $\mathbf{5 - 1 0}$ & $\mathbf{1 1 - 1 5}$ & $>\mathbf{1 5}$ \\
\hline HbAS N = 120 & $56(46.7)$ & $64(53.3)$ & $20(16.7)$ & $16(13.3)$ & $8(6.7)$ & $76(63.3)$ \\
\hline HbSS N = 42 & $26(61.9)$ & $16(38.1)$ & $3(7.1)$ & $1(2.4)$ & $3(7.1)$ & $35(83.3)$ \\
\hline
\end{tabular}

Table 3: Phenotype according to gender and age

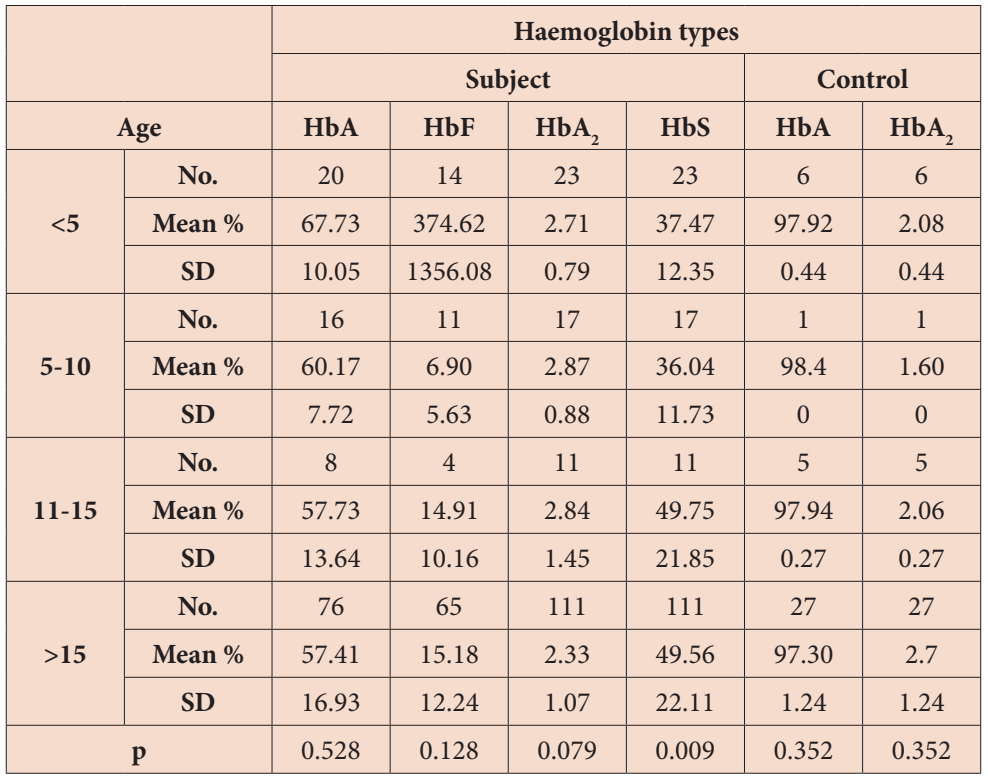

Table 4: Haemoglobin pattern according to age

\section{Discussion}

Sickle cell disease is a major contributor to mortality and morbidity across the Middle East [17]. This retrospective study aimed to estimate the prevalence of haemoglobin patterns amongst patients with sickle cell disease (SCD) in Kuwait. As expected, HbAS was the most common phenotype amongst patients with SCD [18], and no differences were observed in the distribution of phenotypes between males and females or according to age.

$\mathrm{HbA}$ is the predominant haemoglobin in healthy adults, with reports suggesting that it contributes to approximate $98 \%$ of the haemoglobin load. In line with this, and illustrating the validity of our data, we observed a mean percentage of $97.5 \% \mathrm{HbA}$ in our control group. That HbS was not detected in any control samples demonstrates that our assays are not associated with false 
positives, providing reassurance in the identification of SCD patients. Less than $1 \% \mathrm{HbF}$ values detected in our control samples represent a lack of sensitivity in assays, or that the level of $\mathrm{HbF}$ in our study population is lower than in other previously studied population.

As per previous studies, HbF levels were markedly raised in HbAS patients and HbSS patients compared to controls [12]. Although there were no significant differences in $\mathrm{HbF}$ levels amongst males and females, or according to age, $\mathrm{HbF}$ was raised in the youngest age group, as expected given the dominance effect of $\mathrm{HbF}$ in the first few months of newborn infants. In line with previous studies, there were no differences between patients and controls with respect to $\mathrm{HbA}_{2}$ levels, Shu et al. suggested that coelution of $\mathrm{HbS}$ adducts, including glycated $\mathrm{HbS}$. with $\mathrm{HbA}_{2}$ also contributes to increased measured $\mathrm{HbA}_{2}$ concentrations Whereas $\mathrm{HbA}$ levels were markedly reduced in HbAS patients compared to controls [22].

$\mathrm{HbS}$ was only found in the patient group, and was significantly higher in the HbSS group. However, in contrast to previous studies, we did observe differences in $\mathrm{HbA}, \mathrm{HbA}_{2}$ and $\mathrm{HbS}$ according to gender [23,24]. The similarities in $\mathrm{HbS}$ levels between the HbSS and $\mathrm{HbAS}$ groups is a result of all HbSS patients (including those in exclusion criteria) receiving a blood transfusion. The number of patients with accent blood transfusion included in this study is 144 .

Further community based studies should be conducted to determine whether these differences are unique to our hospital-based population or are reflective of the general Kuwaiti SCD population. The variation in the prevalence of haemoglobin phenotype patterns between patients and controls is reflective of previous studies, and underpins screening and diagnostic testing within our population.

There were some limitations to this study. Due to the retrospective nature of the study there was some level of missing data throughout the dataset. In addition, this was a hospital based study and therefore may not be fully representative of the general population. However, our sample number was sufficient to examine differences between the populations and to accurately determine the prevalence of $\mathrm{Hb}$ phenotype patterns amongst our population.

In summary, this study has described the distribution of $\mathrm{Hb}$ phenotypepatterns in a Kuwaiti SCD population. The knowledge of the prevalence $\mathrm{Hb}$ phenotypepatterns encountered within our region is important to ensure that the formulation of diagnostics, preventative strategies and therapeutic options is appropriate to the patients requiring care. $\mathrm{HbA}_{2}$ does not differentiate between patients and controls; however, changes in levels of $\mathrm{HbA}, \mathrm{HbS}$, and $\mathrm{HbF}$ are important for diagnosis and treatment strategies. HPLC is a rapid, sensitive and reliable test for determining the presence of $\mathrm{Hb}$ patterns phenotype within a sample.

\section{Acknowledgement}

The authors are thankful to www.manuscriptedit.com for providing English language editing and proofreading services for this manuscript.

\section{References}

1. Clarke GM, Higgins TN (2000) Laboratory investigation of haemoglobinopathies and thalassemias: review and update. Clin Chem 46: 1284-90.

2. Stuart MJ, Nagel RL (2004) Sickle-cell disease. Lancet 364: 1343-60.

3. Angastiniotis M, Modell B, Englezos P, Boulyjenkov V (1995) Prevention and control of haemoglobinopathies. Bull World Health Organ 73: $375-86$.

4. Kaur M, Dangi CBS, Singh M (2013) An overview on sickle cell disease profile. Asian J Pharm Clin Res 6: 25-37.

5. Okpala IE (2004) Epidemiology, genetics and pathophysiology of sickle cell disease In: Practical Management of Haemoglobinopathies, Blackwell Publishing, UK.

6. Williams TN (2006) Human red blood cell polymorphisms and malaria. Curr Opin Microbiol 9: 388-94.

7. Williams TN (2006) Red blood cell defects and malaria. Mol Biochem Parasitol 149: 121-7.

8. Madigan C, Malik P (2006) Pathophysiology and therapy for haemoglobinopathies. Part I: sickle cell disease. Expert Rev Mol Med 8: 1-23.

9. Di Nuzzo DV, Fonseca SF (2004) Sickle cell disease and infection. J Pediatr 80: 347-54.

10. Creary M, Williamson D, Kulkarni R (2007) Sickle cell disease: current activities, public health implications, and future directions. J Womens Health 16: 575-82.

11. Piel FB, Patil AP, Howes RE, Nyangiri OA, Gething PW, et al. (2013) Global epidemiology of sickle haemoglobin in neonates: a contemporary model based map and population estimates. Lancet 381: 142-51.

12. Piel FB, Patil AP, Howes RE, Nyangiri OA, Gething PW, et al. (2010) Global distribution of the sickle cell gene and geographical confirmation of the malaria hypothesis. Nat Commun 1: 10.1038/ncomms1104.

13. Bunn HF (1997) Pathogenesis and treatment of sickle cell disease. N Engl J Med 337: 762-9.

14. Kaul DK, Fabry ME, Nagel RL (1996) The pathophysiology of vascular obstruction in the sickle sundromes. Blood Rev 10: 29-44.

15. Bunn HF (1994) Hemoglobin structure, function and assembly In: Sickle Cell Disease: Basic Principles and Clinical Practice, Lippincott - Raven Press Publisher, USA.

16. Nagel RL, Fabry ME, Steinberg MH (2003) The paradox of hemoglobin SC disease. Blood Rev 17: 167-78.

17. Al-Qaoud N, Al-Shami E, Prakash P (2015) Anemia and associated factors among Kuwaiti preschool children and their mothers. Alexandria J Med 51: 161-6.

18. Marouf R, D'souza TM, Adekile AD (2002) Hemoglobin electrophoresis and hemoglobinopathies in Kuwait. Med Princ Pract 11: 38-41. 
19. AlMulla AMF, Agab AW, Almannai LS, Henari FZ (2011) Visible and near-infrared absorption properties of blood from sickle cell patients and normal individuals. RCSIsmj-Bahrain 4: 81-3.

20. Adeyemo T, Ojewunmi O, Oyetunji A (2014) Evaluation of high performance liquid chromatography (HPLC) pattern and prevalence of beta-thalassaemia trait among sickle cell disease patients in Lagos, Nigeria. Pan Afr Med J 18: 71.

21. Joutovsky A, Hadzi-Nesic J, Nardi MA (2004) HPLC retention time as a diagnostic tool for hemoglobin phenotype and hemoglobinopathies: a study of 60000 samples in a clinical diagnostic laboratory. Clin Chem 50: 1736-47.

22. Ajjack EA, Awooda HA, Abdalla SE (2014) Haemoglobin patterns in patients with sickle cell haemoglobinopathies. Int J Haematol Disord 1: 8-11.

23. Shu DD, Krauss JS, Bures K (1996) Influence of hemoglobin S adducts on hemoglobin A2 qualification by HPLC. Clin Chem 42: 1113-4.

24. Jeddoa ZMA (2011) Evaluation of (HPLC) Patterns of Sickle Cell Anaemia Patients in Comparison with Apparently Healthy Individuals. Karbala J Med 4: 980-7. 